\title{
Precise Control of Movement Kinematics by Optogenetic Inhibition of Purkinje Cell Activity
}

\author{
Shane A. Heiney, ${ }^{1}$ Jinsook Kim, ${ }^{2}$ George J. Augustine, ${ }^{2,3,4}$ and Javier F. Medina ${ }^{1}$ \\ ${ }^{1}$ Psychology Department, University of Pennsylvania, Philadelphia, Pennsylvania 19104, ${ }^{2}$ Lee Kong Chian School of Medicine, Nanyang Technological \\ University, Singapore 637553, Singapore, ${ }^{3}$ Center for Functional Connectomics, Korea Institute of Science and Technology, Seoul, 136-791 Republic of \\ Korea, and ${ }^{4}$ Institute of Molecular and Cell Biology, Singapore 138673, Singapore
}

Purkinje cells (PCs) of the cerebellar cortex are necessary for controlling movement with precision, but a mechanistic explanation of how the activity of these inhibitory neurons regulates motor output is still lacking. We used an optogenetic approach in awake mice to show for the first time that transiently suppressing spontaneous activity in a population of PCs is sufficient to cause discrete movements that can be systematically modulated in size, speed, and timing depending on how much and how long PC firing is suppressed. We further demonstrate that this fine control of movement kinematics is mediated by a graded disinhibition of target neurons in the deep cerebellar nuclei. Our results prove a long-standing model of cerebellar function and provide the first demonstration that suppression of inhibitory signals can act as a powerful mechanism for the precise control of behavior.

Key words: basket cells; disinhibition; eyeblink; forward model; inverse model; molecular layer interneurons

\section{Introduction}

Converging evidence indicates that PCs of the cerebellar cortex are an essential component of the neural machinery necessary for controlling movements and keeping them finely tuned (Dow and Moruzzi, 1958; Ivry and Keele, 1989; Thach et al., 1992; Mauk et al., 2000; Manto and Pandolfo, 2002). First, PCs project to neurons in the vestibular or deep cerebellar nuclei (DCN), many of which have relatively direct access to motoneurons, and to motor-related areas in the cerebrum (Ito, 1984). Second, the most salient symptom of cerebellar dysfunction is ataxia: if PCs are damaged, movements lose precision and become variable, uncoordinated, and incorrectly timed, both in human patients (Bastian et al., 1996; Spencer et al., 2003) and in nonhuman animal models (Dow and Moruzzi, 1958; Walter et al., 2006). Third, extracellular recordings from cerebellar cortex in a variety of motor tasks have revealed that the firing rate of individual PCs is strongly modulated, varying up and down according to kinematic parameters of the movement such as its speed, direction, or duration (Shidara et al., 1993; Thier et al., 2000; Roitman et al.,

Received Oct. 24, 2013; revised Dec. 18, 2013; accepted Dec. 28, 2013.

Author contributions: S.A.H., J.K., G.J.A., and J.F.M. designed research; S.A.H. and J.K. performed research; G.J.A. contributed unpublished reagents/analytic tools; S.A.H. and J.K. analyzed data; S.A.H., J.K., G.J.A., and J.F.M. wrote the paper.

This work was supported by the Searle Scholars Program, the National Institutes of Health (Grant R01 MH093727 to J.F.M.), the National Research Foundation of Singapore (Competitive Research Programme grant to G.J.A.), and the World Class Institute Program of the National Research Foundation of Korea funded by the Ministry of Education, Science and Technology of Korea (Grant WCI 2009-003 to G.J.A.). We thank E. Boyden for assistance with optogenetics, the University of Pennsylvania Cell \& Developmental Biology Imaging Core for assistance with imaging, J.C. Lopez for contributing to preliminary mapping experiments, and L. Wen and S. Tsuda for helpful comments.

The authors declare no competing financial interests.

Correspondence should be addressed to Javier Medina, Department of Psychology, University of Pennsylvania, 3720 Walnut St, Philadelphia, PA 19104. E-mail: jmed@psych.upenn.edu.

DOI:10.1523/JNEUROSCI.4547-13.2014

Copyright $\odot 2014$ the authors $\quad 0270-6474 / 14 / 342321-10 \$ 15.00 / 0$
2005; Medina and Lisberger, 2009). Although all of this evidence clearly establishes the PC as a key player in the control of movement, a mechanistic understanding of how PC signals are used to elaborate and shape motor commands is still lacking.

To understand how PC signals contribute to motor control, it is necessary to consider that PCs are inhibitory projection neurons (Ito, 1984) and that they are spontaneously active at unusually high firing rates in vivo (50-100 Hz; Thach, 1968). Given these peculiar properties, it was suggested early on that PCs could exert control by transiently reducing their firing rate (i.e., generating a brief "pause") and activating motor areas via disinhibition of the DCN (Albus, 1971; Ito, 1984, 2001). In support of this "disinhibition hypothesis," in vitro experiments have demonstrated that DCN neurons can be reliably activated with high temporal precision by a brief suppression of their inhibitory inputs (Gauck and Jaeger, 2000). Furthermore, in vivo recordings have shown that the high spontaneous activity of PCs is occasionally interrupted by a brief pause, which is often synchronized among nearby cells (Shin and De Schutter, 2006; De Zeeuw et al., 2011) and is temporally correlated with ongoing movements (Noda and Suzuki, 1979; Jirenhed et al., 2007; Cao et al., 2012).

Although the "disinhibition hypothesis" provides the foundation for many current models of cerebellar function (Houk et al., 1996; Medina and Mauk, 2000), its most fundamental tenet remains untested. It has not been possible to establish a causal link between suppression of PC firing, disinhibition of DCN neurons, and the control of movement because, until now, there was no way to precisely and selectively inactivate PCs on behaviorally relevant timescales in vivo. We solved this problem with an optogenetic strategy that allowed us to briefly inhibit PCs while simultaneously examining the effects on downstream DCN neurons and behavior. 


\section{Materials and Methods}

Subjects and surgery. All procedures were performed in adult wild-type C57BL/6 (Jackson Laboratories; $n=10$ ) or nNOS-ChR2 BAC transgenic mice ( $n=11$; Asrican et al., 2013; Tsuda et al., 2013) of both sexes in accordance with protocols approved by the University of Pennsylvania Animal Care and Use Committee based on guidelines of the National Institutes of Health. A single surgery was performed stereotaxically to implant both a "headplate" for head restraint and a chamber for extracellular recording and stimulation in the cerebellum. During surgery, mice were anesthetized with isoflurane $\left(1.5-2 \%\right.$ by volume in $\mathrm{O}_{2}$; SurgiVet) and kept on a heating pad to maintain body temperature. In addition, a nonsteroidal anti-inflammatory drug (Meloxicam) was given perioperatively to reduce swelling and provide postoperative analgesia. A midline incision was made to expose the skull and the underlying fascia was cleared with cotton swabs. Two small screws were placed on either side of the midline near bregma and a thin layer of VetBond adhesive $(3 \mathrm{M})$ was spread over the cranial surface and around the screws. A thin stainless steel "headplate" was then placed over bregma using a custombuilt stereotaxic adaptor and was secured to the screws and skull using dental acrylic (Jet). A third screw was implanted in the bone above the left cerebellar hemisphere to serve as a reference for stimulation and recording. After this, an $\sim 3$-mm-diameter craniotomy was performed over the right cerebellar hemisphere centered $\sim 6.5 \mathrm{~mm}$ posterior and $2.0 \mathrm{~mm}$ lateral from bregma. This exposed several lobules of the cerebellar cortex, including paravermal IV/V, VI, and hemispheric simplex and crus I, as well as the inferior colliculus, and allowed our recording and stimulation tracks to be chosen based on both surface landmarks and stereotaxic coordinates. A plastic cylinder (inner diameter $=3.5 \mathrm{~mm}$ ) serving as a chamber was then implanted over the craniotomy and affixed to the skull with dental acrylic. A thin layer of antibiotic ointment was applied on top of the dura and the chamber was filled with a fast-curing silicone elastomer (Kwik Sil or Kwik Cast; WPI) that could be removed before each daily experiment to give access to the brain. Care was taken to reduce bleeding and swelling during the craniotomy so that the dural surface, which was left intact, would remain healthy for many weeks of daily recording. Despite this, it was necessary to remove accumulated scar tissue periodically to allow easy penetration of the recording and stimulation probes.

Monitoring behavior. All experiments were performed in awake, headfixed mice standing on a foam cylinder treadmill mounted on low friction bearings so that the mice could walk freely (Chettih et al., 2011). However, data were collected only during intervals when the mice were calm and still. Facial movements ipsilateral to the recording and stimulation sites were monitored under infrared illumination using a high speed monochrome camera (Allied Vision) interfaced with MATLAB using custom-written software and the Video Acquisition Toolbox. Frame acquisition was triggered with digital pulses generated by a Sys 3 acquisition system (200 frames/s; TDT) and kept in register with neural data and stimulation timestamps acquired simultaneously by the TDT system. Trials with obvious facial movement, mostly of the whiskers, in the prestimulus control period were excluded from analysis.

Electrical stimulation of cerebellar cortex. We used a platinum iridium monopolar electrode $(100 \mathrm{~K} \Omega$, Alpha Omega) to microstimulate (10$500 \mathrm{~ms}$ pulse trains; $250 \mu \mathrm{s}$ biphasic pulses; $300-500 \mathrm{~Hz}$ ) in different areas of cerebellar cortex, including paravermal and hemispheric lobules IV/V,VI, and crus I. The stimulating electrode was advanced in steps of $100-250 \mu \mathrm{m}$ starting just below the dural surface and currents in the range of 30-300 $\mu \mathrm{A}$ were tested at each site, with delayed movements usually not occurring until $>100 \mu \mathrm{A}$. In some experiments, marking lesions were performed by passing a $100-\mu \mathrm{A}$-tip positive current through the stimulating electrode for $10 \mathrm{~s}$.

Electrical stimulation of DCN. We used a platinum iridium monopolar electrode ( $100 \mathrm{~K} \Omega$; Alpha Omega) to microstimulate (10-500 ms pulse trains; $250 \mu$ s biphasic pulses; $300-500 \mathrm{~Hz}$ ) in different areas of DCN, including anterior interpositus, the dorsolateral hump, and medial portions of the lateral nucleus. To avoid possible damage to the cortical eyeblink region, the electrode was angled -10 degrees so that the tracks traveled through a more posterior region of lobule simplex. Electrodes were advanced in steps of 50-100 $\mu \mathrm{m}$ and currents in the range of 1-15 $\mu \mathrm{A}$ were systematically tested to identify the threshold for evoking movement. Stimulus driven upward slow phase nystagmus and other apparently vestibular-related movements were used as an indication that the electrode had reached the vestibular nuclei, which aided in locating the relatively narrow strip of anterior interpositus along the dorsal-ventral axis. In some experiments, microstimulation was performed with a 15- to $20-\mu \mathrm{m}$-tip glass micropipette. This allowed us to ionotophoretically inject $10 \%$ tetramethylrhodamine-conjugated dextran (TDA; Invitrogen) to mark the site of microstimulation in the DCN and to retrogradely label Purkinje cell projections to it.

Optical stimulation. Photostimulation of cerebellar cortex was performed using a fiber optic probe connected to an analog-controlled 473 nm laser (Blue Sky Research). Individual fiber optic probes were manufactured by hand using $100-\mu \mathrm{m}$-core silica-clad fibers (Thorlabs) reinforced with hypodermic tubing, which were pulled to a fine taper by applying heat and were cleaved to give a final tip diameter of $20-30 \mu \mathrm{m}$. These finer tips allowed easy penetration of the dura and focal light stimulation of the tissue. Because the silica cladding is fused to the core and they expand together when heated, the waveguide properties of the optical fiber were not appreciably disrupted by this manipulation. Each photostimulation trial consisted of a single pulse of light, rather than a pulse train. Three parameters of the light pulse were randomly varied from trial to trial: intensity $0.1-5 \mathrm{~mW}$, duration $50-500 \mathrm{~ms}$, and rise time $0-200 \mathrm{~ms}$.

Single unit recording. All single unit recordings were performed using 80- $\mu \mathrm{m}$-diameter 2-5 $\mathrm{M} \Omega$ tungsten microelectrodes (FHC). Spikes were sorted using principal component analysis after the extracellular signals had been digitized at $25 \mathrm{kHz}$ and band-pass filtered between $0.1-8 \mathrm{kHz}$ (Sys3; TDT). For simultaneous recording and photostimulation in cerebellar cortex, the fiber optic probe was either glued directly to the electrode (for distances of 100-200 $\mu \mathrm{m}$; intertip distance measured under microscope) or was moved independently using a second stereotaxic micromanipulator (for distances $>200$ $\mu \mathrm{m})$. Purkinje cells were identified based on the presence of a characteristic pause in simple spike firing after complex spikes (Thach, 1968), whereas units without complex spikes and a rapid (1-2 ms latency) increase in firing rate after photostimulation were classified as putative molecular layer interneurons. For simultaneous photostimulation in cerebellar cortex and recording in DCN, the fiber optic probe was always moved independently of the electrode using a second stereotaxic micromanipulator.

In vitro experiments. To confirm the specificity of ChR 2 expression, in vitro patch-clamp recording and photostimulation of different cerebellar neurons were performed in 200 - to $300-\mu \mathrm{m}$-thick sagittal cerebellar slices, as described previously (Asrican et al., 2013). The recordings were conducted at room temperature.

Anatomical tracing. Retrograde tracing of Purkinje cell projections to the DCN was performed by iontophoretically injecting $10 \%$ tetramethylrhodamine-conjugated dextran (TDA; Invitrogen) through a glass pipette (15-20 $\mu \mathrm{m}$ tip size). The iontophoretic parameters were 20 $\mu \mathrm{A}, 10 \mathrm{~s}$ tip-negative pulses with a $50 \%$ duty cycle for $15-20 \mathrm{~min}$. Before removing the pipette from each track, we waited $15 \mathrm{~min}$ after the injection to minimize spreading of the dye along the track. When injections were performed in the eyeblink region of the DCN, the iontophoretic protocol was found to induce eyelid closure at the offset of the pulses, a finding that we used to verify that injections were being made in the correct location. A conservative survival time of $48 \mathrm{~h}$ after TDA injections was used to ensure adequate retrograde transport of the dye, although the vendor (Invitrogen) estimates much faster transport times.

Histology. Mice were deeply anesthetized with isoflurane and transcardially perfused with $0.1 \mathrm{~m}$ PBS followed by $4 \%$ paraformaldehyde in $0.1 \mathrm{~m}$ PBS. Brains were postfixed for at least $4 \mathrm{~h}$ and cryoprotected in $30 \%$ sucrose until they equilibrated (1-2 d). Coronal sections were cut at $50 \mu \mathrm{m}$ thickness on a cryostat (Leica) and immediately mounted on a glass slide. For mice with marking lesions in the cerebellar cortex, mounted sections were stained with cresyl violet using standard histological procedures, dehydrated, defatted, and coverslipped. For the TDA-injected mice, mounted sections were stained 
A
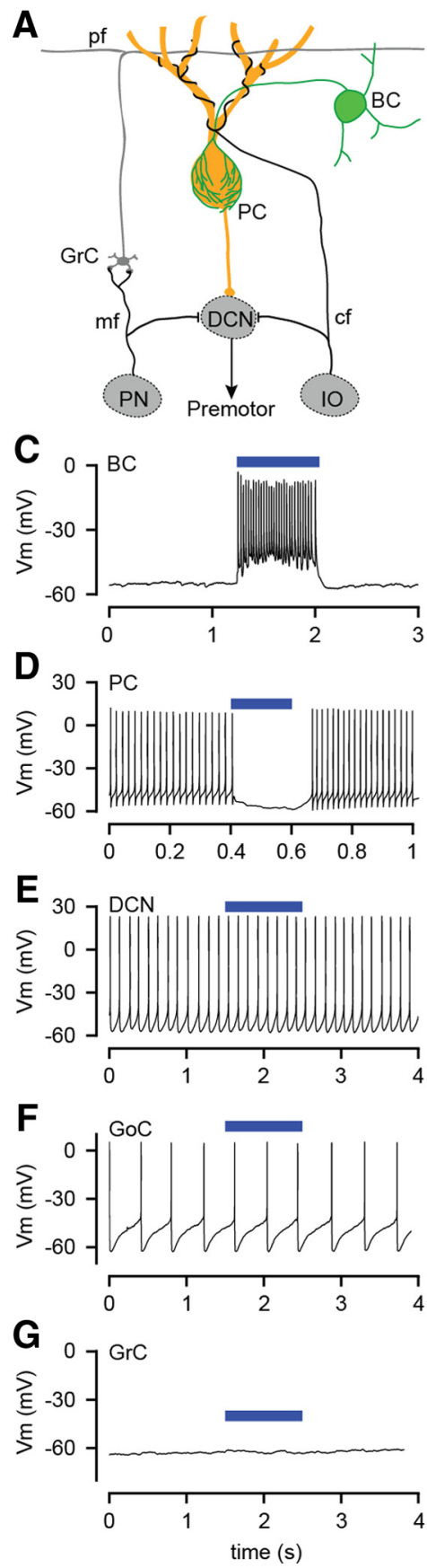
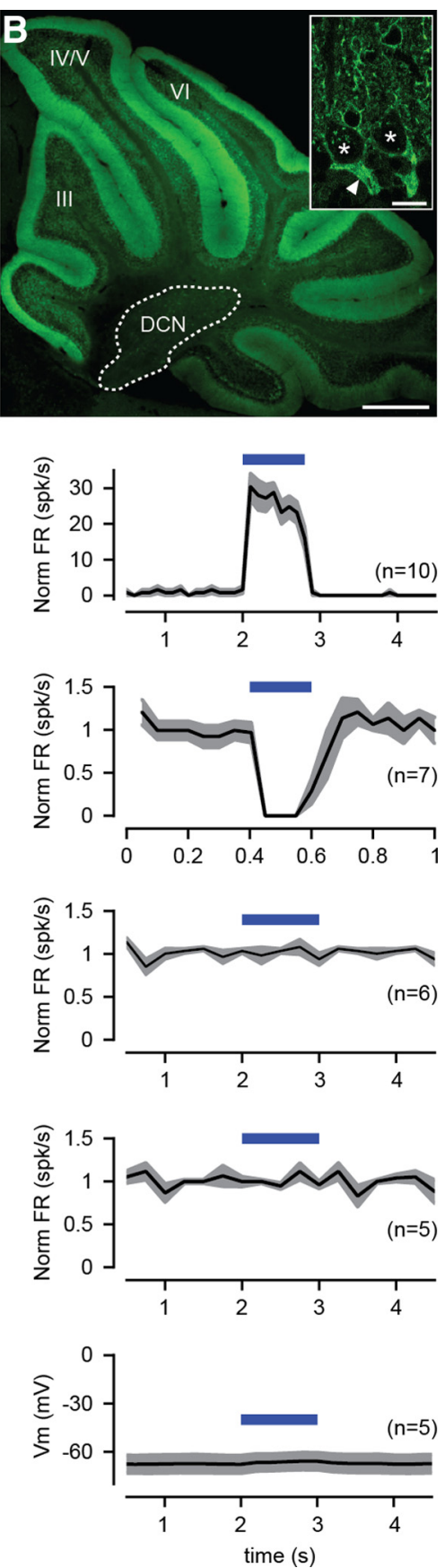

Figure 1. Optogenetic strategy for inhibiting PCS. A, Simplified diagram of cerebellar cortex. BC, basket cell; $C F$, climbing fiber; $\mathrm{GrC}$, granule cell; 10, inferior olive; MF, mossy fiber; PF, parallel fiber; PN, pontine nuclei. $\boldsymbol{B}$, ChR2 expression in MLIs (green), including the pinceau structure of the basket cell axon (indicated by triangle in inset; PC somata indicated by asterisks; scale bar, 15 $\mu \mathrm{m})$. Lobules of cerebellar cortex are indicated by Roman numerals. Scale bar, $400 \mu \mathrm{m}$; distance of section from midline is $\sim 1.1$ $\mathrm{mm}$. $\mathbf{C}-\mathbf{G}$, Whole-cell patch-clamp recordings of different cerebellar neuron types in sagittal cerebellar slices (age P20-P39) during photostimulation (blue bar). Individual examples on left and population average change in normalized firing rate $(\boldsymbol{C}-\boldsymbol{F})$ or membrane potential $(\boldsymbol{G})$ on right. Neuronal types and the number of neurons in the averages are indicated in each panel. Average membrane potential is reported for granule cells because they did not fire action potentials. GoC, Golgi cell. Error bars indicate SEM.

with NeuroTrace Green Fluorescent Nissl (Invitrogen) using the vendor-recommended protocol with a 100-fold dilution of the stain and coverslipped with Prolong Gold (Invitrogen). For the YFP mice, mounted sections were rehydrated with PBS and coverslipped with Prolong Gold. All histological procedures using fluorescent signals were performed in the dark under a dim red illumination. Sections were imaged on a widefield microscope (Axioplan 2; Zeiss) under bright-field (cresyl violet) or epifluorescent illumination or on a laser scanning confocal microscope (LSM510 META; Zeiss).

Data analysis. Data were analyzed using custom-written programs and the Image Processing Toolbox in MATLAB. To measure eyelid movements, we calculated the fraction of eyelid closure (FEC) on each video frame, which is proportional to the diameter of the minor axis of the ellipse created by the boundary between the eyelids and the iris/pupil. This was achieved by selecting an $\sim 100$ pixel $\times 100$ pixel rectangular region of interest (ROI) in the video frames that corresponded to the pupil, iris, and surrounding fur and converting the grayscale image to a thresholded binary image. The threshold value was carefully selected during each session to give the best discriminability between the dark pupil/iris and the lighter surrounding fur of the eyelids. Therefore, in the resulting binary image, the pupil and iris had values of 0 and the fur had a value of 1 . To eliminate "salt and pepper" noise in the binary image, a 5 pixel $\times 5$ pixel median filter was applied to the grayscale image before converting to binary. The binary image was then summed along both dimensions to calculate the pixel area in the ROI consisting of fur (eyelids). These raw pixel counts for each frame were linearly transformed into units of FEC, which ranges from 0 (fully open) to 1 (fully closed) based on calibration trials using corneal airpuffs that generated full blinks, and the FEC values for the whole video were converted to time series based on the frame rate of the camera (200 frames/s, 5 ms sample interval).

Photostimulation-driven blinks for different laser intensities or rise times were analyzed by pooling together the data for each session into three discrete bins as follows: laser intensity $(I): I \leq 1,1<I<3, I \geq 3 \mathrm{~mW}$; laser rise time $(R): R \leq 25,25<R<100$, $R \geq 100$ ms. Per-session averages of eyelid position and velocity were then calculated based on these bins and normalized by dividing all traces by the maximum change in position or velocity achieved for that session. Across-session averages were computed by taking the mean of the normalized per session averages for each bin only when a particular session included data in every bin. This guaranteed that the graded effects that we saw in the population data were present within individual sessions as well. Eyelid rise time was quantified as the time constant of the movement for each per-session average (i.e., the time at which the eyelid reached $63 \%$ of its maximum closure in each averaged trace). This was favored over alternative measures such as time of peak closure because the eyelid position traces often exhibited long asymptotic tails in which the peak occurred at or after the end of stimulation but the actual change in position in the final 100 ms was negligible (see Fig. 4C).

The population averaged eyelid position, velocity, and DCN neuron firing rate traces for different laser intensities shown in Figure $5 F$ were calculated based on "laser intensity bins" as above, however, the 
eyelid position, eyelid velocity, and firing rate were not normalized to facilitate a more direct comparison between the neuron firing properties and the eyelid kinematics. The relationship between firing rate and eyelid kinematics shown in Figure 5, $G$ and $H$, was calculated on a trial-by-trial basis for each neuron individually as follows. Either the normalized maximum change in eyelid velocity within an early time window (first 100 $\mathrm{ms}$ ) or position within a late time window (last $100 \mathrm{~ms}$ ) was binned based on quintiles of the percent change in firing rate in the same window relative to a prestimulus control period during that trial. The early window was chosen to select for velocity-related changes in firing rate and the late window was chosen to select for position-related changes. Each bin was then averaged across neurons. A minimum of 27 and a median of 58 trials were used to compute the averages for each neuron.

The details of the statistical tests used to analyze our data are provided within the text of the corresponding section in the paper.

\section{Results}

Optogenetic suppression of PC activity To test the hypothesis that a suppression of PC firing rate is sufficient to generate movement, we had to find a way to transiently and selectively suppress PC activity in vivo. We achieved this with newly developed optogenetic tools that allowed us to take advantage of the well defined synaptic organization of the cerebellar cortex (Fig. 1A). We used an nNOS-ChR2 BAC transgenic mouse line that expresses ChR2 in $>85 \%$ of molecular layer interneurons (MLIs; Fig. 1B; J. Kim and G. J. Augustine, unpublished observations; Tsuda et al., 2013), including in the basket cells (Fig. 1A), which are known to powerfully inhibit PCs (Ito, 1984; Mittmann et al., 2005). Whole-cell and extracellular recordings of individual cells in cerebellar slices from nNOS-ChR2-BAC mice confirmed that ChR2 was functionally expressed only in MLIs (Fig. 1C), and not in Purkinje, DCN, Golgi, or granule cells (Fig. 1D-G). Among the MLIs, basket and stellate cells expressed ChR2 at comparable high levels (i.e., photostimulation-induced action potentials could be elicited in $>80 \%$ of both cell types). Consistent with a previous report (Tsuda et al., 2013), in vitro photostimulation of MLIs was an effective way to suppress PC firing (Fig. 1D).

Similar to the in vitro results, we found that, in awake nNOS-ChR2 BAC mice, photostimulation of the cerebellar cortex through an optical fiber substantially increased the firing rates of putative MLIs near the tip of the fiber (Fig. $2 A$; median increase $=118 \%$, range $=81-260 \%, n=5$ neurons $)$ and resulted in sustained
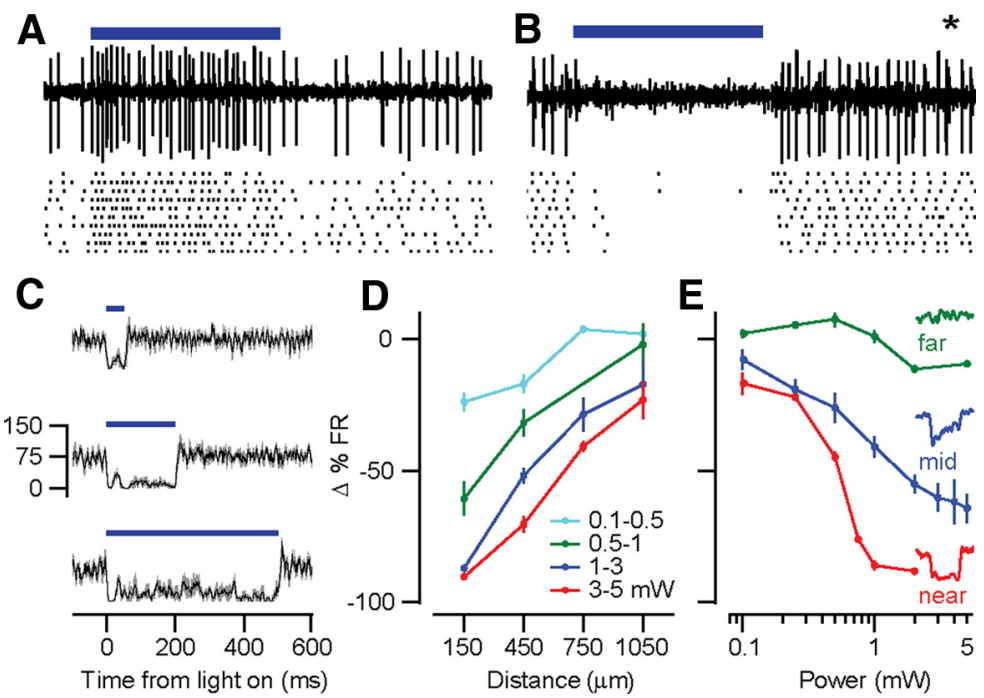

Figure 2. In vivo optogenetic inhibition of PCs. Examples of putative $M L I(A)$, and identified $P C(\boldsymbol{B}$; asterisk indicates complex spike) recorded during in vivo photostimulation (blue bar, $200 \mathrm{~ms}$ ). Top, single trial raw trace; bottom, raster for 10 photostimulation trials. PC inhibition was graded with light duration ( $C ; n=4$ neurons; power, $2 \mathrm{~mW} ; y$-axis in spks $/ \mathrm{s})$ and both the distance of the PCs from the optical fiber and the light intensity $(\boldsymbol{D}, \boldsymbol{E} ; n=17$ neurons). In $\boldsymbol{D}$ powers are binned as indicated, and distances are binned in $300 \mu \mathrm{m}$ intervals (bin centers on $\boldsymbol{X}$-axis). Insets in $\boldsymbol{E}$ show average PSTHs for PCs that are near $(<300 \mu \mathrm{m})$, mid (300-1000 $\mu \mathrm{m})$, and far (>1 mm) from fiber for $200 \mathrm{~ms}$ pulses at $2 \mathrm{~mW}$. Error bars indicate SEM.
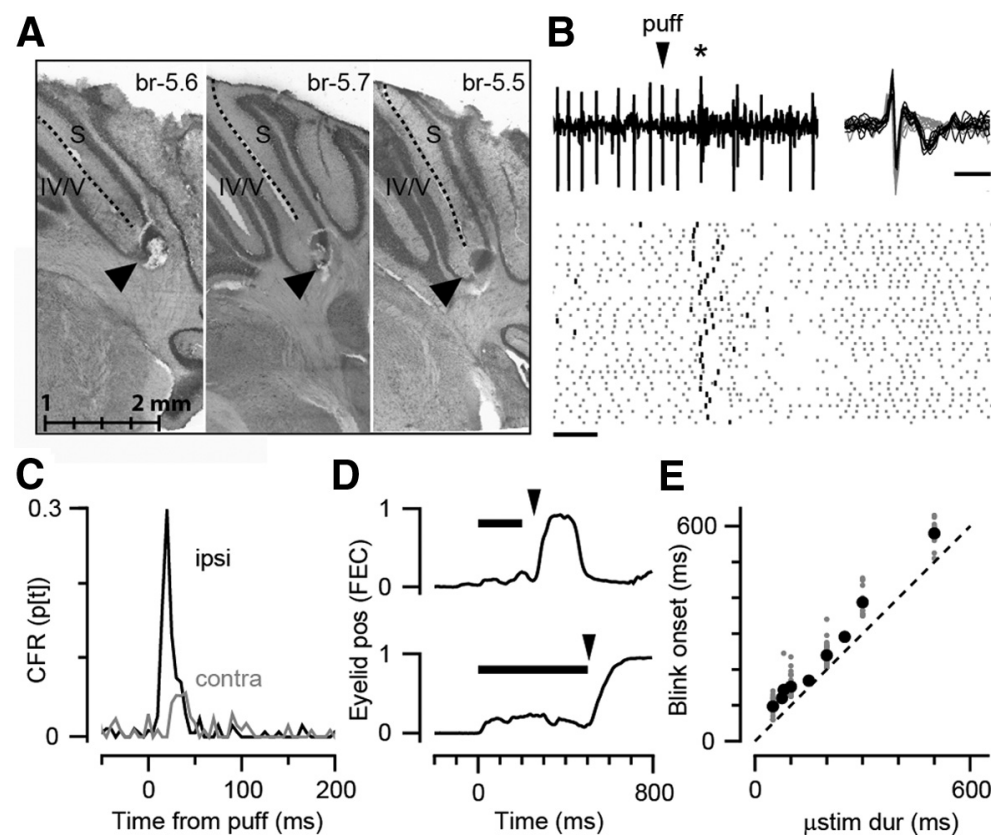

Figure 3. Identification of an "eyeblink" microzone in mouse cerebellar cortex. $\boldsymbol{A}$, Locations of electrolytic lesions in three separate mice, indicated by triangles, in Nissl-stained coronal sections. Distances are relative to bregma (br); calibration bar is lateral distance from midline; lobules indicated by Roman numerals, dashed line is primary fissure). Climbing fibers in this location (recorded as complex spikes in the postsynaptic PC) responded with short latency ( $\sim 20 \mathrm{~ms})$ to corneal air puffs, as indicated by the example neuron shown in $\boldsymbol{B}$. Top, Raw voltage trace from single trial. Downward triangle, puff onset; asterisk, complex spike. Inset, Example spike shapes for simple (gray) and complex spikes (black) from this PC; scale bar, 1 ms. Bottom, Raster for 36 puff trials. Scale bar, $20 \mathrm{~ms}$. C, Average probability of climbing fiber response (CFR; $10 \mathrm{~ms}$ bin size) for ipsilateral ( $n=7$ neurons; black) and contralateral periocular puffs ( $n=3$ neurons; gray). Microstimulation in this location with 100 to $200 \mu$ A biphasic pulse trains of varying durations (single trial examples shown in D; FEC, fraction eyelid closure) resulted in "delayed blinks," blinks that were time locked to the end of stimulation rather than the beginning $(\boldsymbol{E} ; n=165$ trials from 9 sessions). Black bars and downward triangles in $\boldsymbol{D}$ indicate microstimulation period and onset of delayed blink, respectively.

decreases in the firing of identified PCs in the same region (Fig. 2B; asterisk indicates a complex spike, the neural signature of PCs). As expected for this fast inhibitory synapse (Korn and Axelrad, 1980; Mittmann et al., 2005), the suppression of 

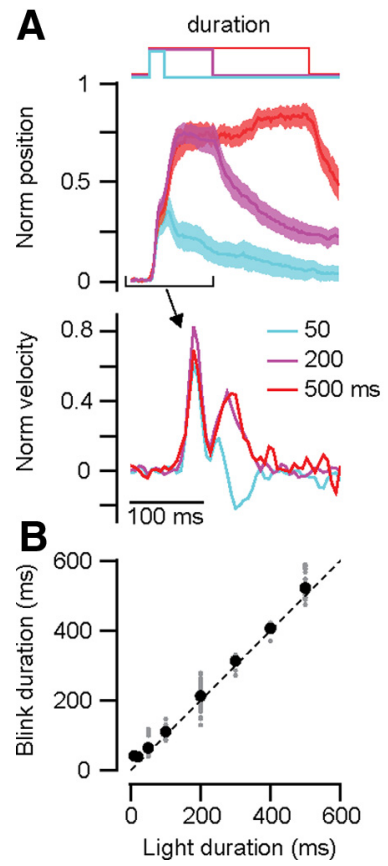
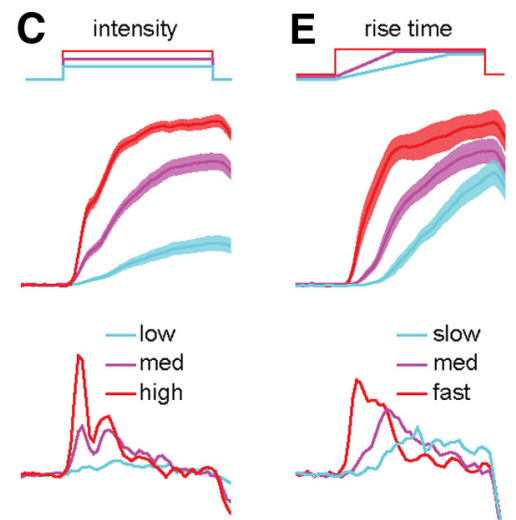

D

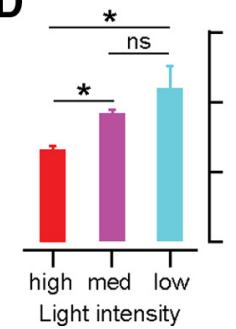

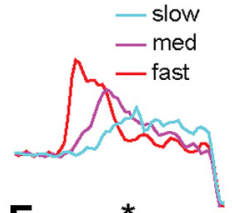

$\mathbf{F}$

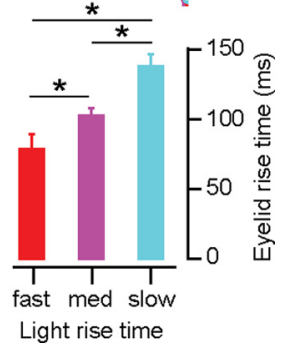

Figure 4. Control of eyeblink timing and kinematics by graded photostimulation. $\boldsymbol{A}$, Per-session averaged eyelid position (top) and velocity (bottom) as a function of time for different light pulse durations (cyan: $50 \mathrm{~ms}$, magenta: $200 \mathrm{~ms}$, red: $500 \mathrm{~ms}$ ). B, Blink duration as a function of different light durations for single trials (gray) and averaged across trials (black; $n=301$ trials across 13 sessions). C, Same format as $\boldsymbol{A}$, but for 200 ms pulses of different light intensities ( $n=890$ trials across 10 sessions; high $\geq 3,1<$ medium $<3$, low $\leq 1 \mathrm{~mW}$ ). $\boldsymbol{D}$, Eyelid rise time calculated for the same data as in $\boldsymbol{C}$ (see Materials and Methods). $\boldsymbol{E}$, Same format as $\boldsymbol{A}$, but for light pulses of different rise times ( $n=668$ trials across 11 sessions; fast $\leq 25,25<$ medium $<100$, slow $\geq 100 \mathrm{~ms}$ ). $\boldsymbol{F}$, Same format as $\boldsymbol{D}$, for data from $\boldsymbol{E}$. Time scale for all panels is as indicated by the schematic laser signal at the top of each column, except for velocity in $\boldsymbol{A}$, which has been expanded to match time scale of other velocity panels as indicated by arrow. Error bars in $\boldsymbol{A}, \boldsymbol{C}$, and $\boldsymbol{E}$ and bars in $\boldsymbol{D}$ and $\boldsymbol{F}$ indicate SEM; not shown for clarity in velocity traces. Asterisks in $\boldsymbol{D}$ and $\boldsymbol{F}$ indicate $p<0.05$ (Fisher's least significant difference test after confirming significance with ANOVA).

The suppression of firing in individual PCs was graded in proportion to the intensity and duration of MLI photostimulation, as well as the distance between the optical fiber and the PC. For PCs closest to the tip of the fiber, light intensities $>1$ $\mathrm{mW}$ caused a near-complete suppression of firing that lasted the entire duration of the light pulse (Fig. 2C; pause duration linearly related to light duration: $r=$ $0.9998, p \ll 0.0001 ; n=4$ PCs). In response to lower light intensities, PCs showed a substantial decrease in firing at the onset of the photostimulation pulse followed by a reduced level of suppression that was graded depending on power (Fig. $2 E$ ). In addition, the suppression of firing was spatially restricted and decreased rapidly with distance (Fig. $2 D$ ) so that PCs $>1$ $\mathrm{mm}$ from the fiber showed very little inhibition and any residual inhibition was only transient (Fig. 2E, green). Therefore, in vivo photostimulation of MLIs is an effective way to cause temporally precise suppression of firing in spatially restricted PC populations. The overall level of suppression in the population depends on the intensity of photostimulation, which can be adjusted to concurrently control how many PCs are inhibited and how much the firing rate is decreased in individual PCs.

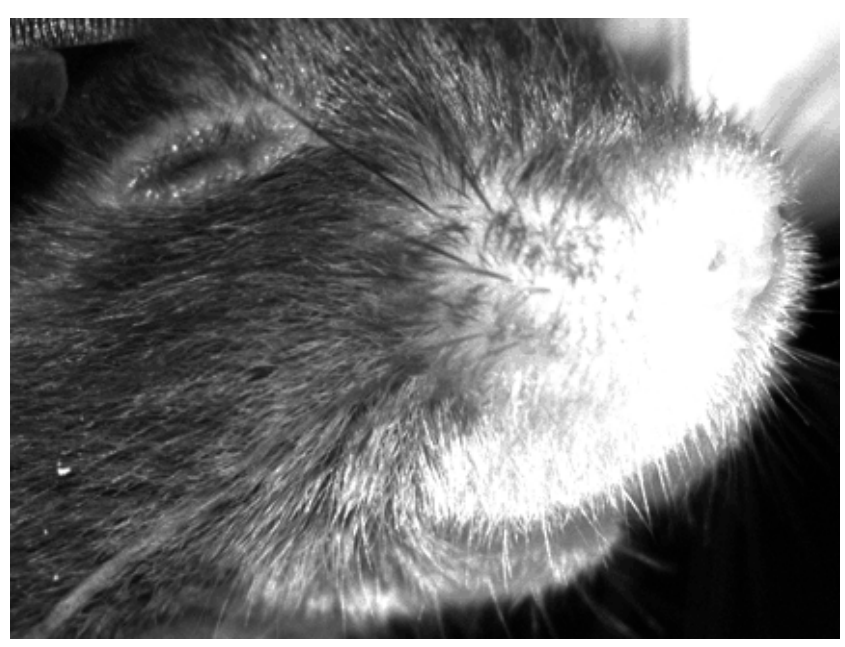

Movie 1. Slow motion video showing example photostimulation-evoked eyelid closure on a single trial. Video was captured at 200 frames/s and is replayed at 20 frames $/ \mathrm{s}$. Overlaid blue square indicates duration of stimulation pulse. Light intensity was $3 \mathrm{~mW}$.

PC activity occurred very rapidly (Fig. $2 B, C$; median latency to $20 \%$ reduction in firing $=2 \mathrm{~ms}$; range $=1-4 \mathrm{~ms}$ ). Importantly, we never found any identified PCs that increased their activity in response to photostimulation in our in vivo experiments ( $n=21$ neurons), which is consistent with the observation that nNOS-ChR2-BAC mice do not express ChR2 in PCs or in their excitatory granule cell inputs (Fig. $1 B$, inset; Fig. $1 D, G)$.
Identification of an eyeblink area in mouse cerebellar cortex To determine how suppressing PC activity affects behavior, we focused on eyelid movements because these can be precisely measured in awake mice (Chettih et al., 2011) and their kinematic properties have been the subject of previous analyses of motor learning (Mauk and Ruiz, 1992; Medina et al., 2000; Koekkoek et al., 2003; Chettih et al., 2011). The areas of cerebellar cortex that are involved in the control of eyelid movements are known in other animal species (Hesslow, 1994; Garcia et al., 1999; Mostofi et al., 2010), but not in mice. Therefore, we first performed a series of experiments to establish the location of a blink-related area in mouse cerebellar cortex.

We mapped out areas of lobules IV/V, simplex, and crus 1 using electrical microstimulation and extracellular single-unit recordings. The marking lesions in Figure $3 A$ (black triangles) pinpoint an area of mouse cerebellar cortex that satisfied two criteria used in previous studies to define an eyeblink microzone in other animal species (Hesslow, 1994; Mostofi et al., 2010). First, PCs within this location received climbing fiber input that was time locked to a periocular puff stimulus, with median latencies of $22 \mathrm{~ms}$ (range $=17.5-27 \mathrm{~ms}, n=7$ neurons; Fig. $3 B, C$ ). Three of these climbing fibers were tested with both ipsilateral and contralateral puffs and all showed reliable responses only to ipsilateral puffs (Fig. 3C), which is consistent with previous work (Mostofi et al., 2010). Second, microstimulation with high electrical currents $(>100 \mu \mathrm{A})$ in the same location generated a characteristic "delayed blink," a pronounced eyelid closure that occurs with a fixed latency after terminating the stimulation regardless of stimulus duration (Hesslow, 1994; Fig. 3D,E). Histological examination 


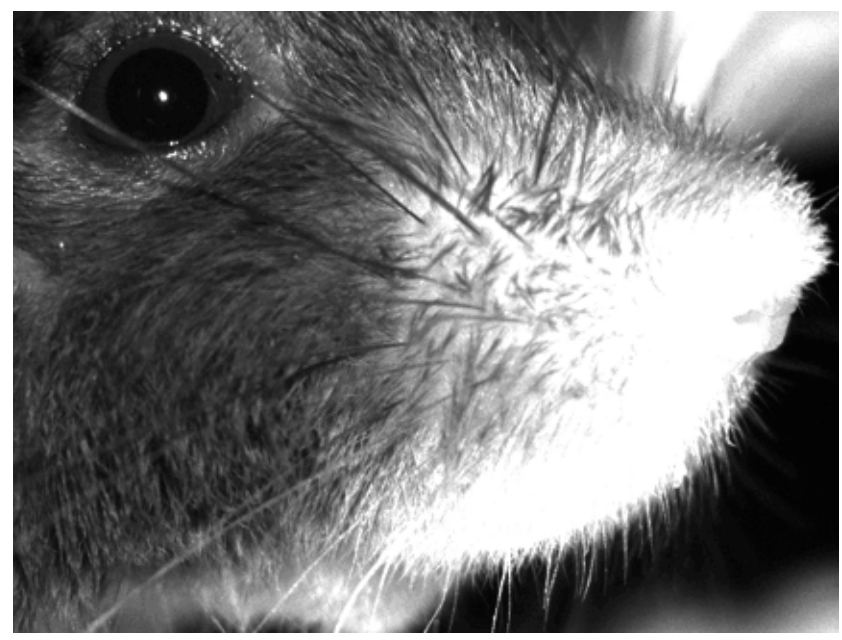

Movie 2. Slow motion video showing example photostimulation-evoked mouth opening on a single trial. Same format as Movie 1. Light intensity was $0.5 \mathrm{~mW}$.

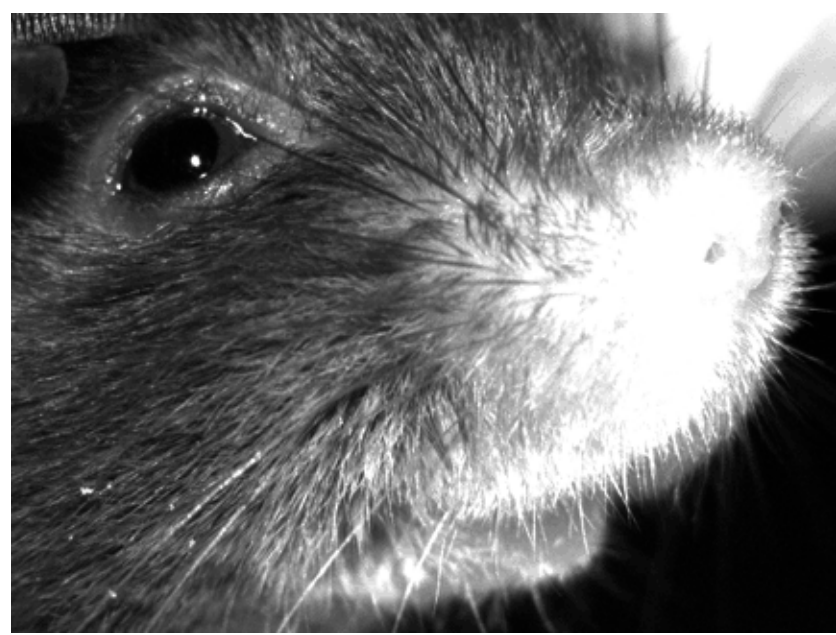

Movie 3. Slow motion video showing example photostimulation-evoked cheek movement on a single trial. Same format as Movie 1. Light intensity was $2 \mathrm{~mW}$.

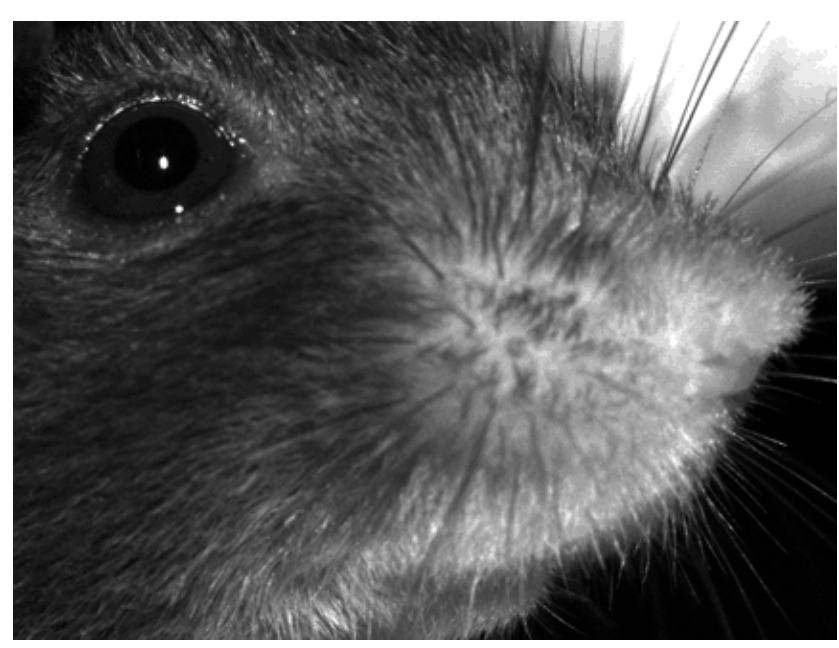

Movie 4. Slow motion video showing example photostimulation-evoked vibrissal pad movement on a single trial. Same format as Movie 1. Light intensity was $2 \mathrm{~mW}$. of electrolytic lesions made in this location revealed that the mouse eyeblink microzone is at the floor of the primary fissure $\sim 5.6 \mathrm{~mm}$ posterior from bregma (Fig. $3 A$ ), a location that is near eyeblink microzones previously identified in rabbit lobules V/HVI (Garcia et al., 1999; Mostofi et al., 2010).

\section{Control of movement kinematics via graded suppression of PC activity}

Transiently reducing PC activity via photostimulation of MLIs in the eyeblink microzone resulted in closure of the ipsilateral eyelid (Fig. 4; Movie 1). This photostimulation-driven eyelid movement mirrored the "delayed blink" evoked by electrical microstimulation (Fig. $3 D, E$ ), except that it was often smaller in amplitude and was always time locked to the onset of the photostimulation (eyelid movement amplitude for $5 \mathrm{~mW}$ photostimulation $=0.34 \pm 0.23 \mathrm{FEC}($ mean $\pm \mathrm{SD})$; median latency to $20 \%$ of maximum velocity $=20 \mathrm{~ms}$, range $=10-55$ $\mathrm{ms}, n=10$ sessions). In contrast, photostimulation of MLIs in nearby locations of paravermal lobules IV-VI elicited other orofacial movements, including mouth opening, cheek/lip lifting, and forward thrusting of the vibrissa (Movies 2, 3, 4). All of these movements were evoked reliably with light intensities as low as $0.5 \mathrm{~mW}$, but no movements were observed when the optical fiber was placed just above the dura or when photostimulation was performed in the cerebellar cortex of wild-type mice. Together, these results demonstrate that transient decreases in PC activity are sufficient to drive movements that are specific to the cerebellar cortical area where the inhibited PCs are located.

Previous recording studies have shown that $\mathrm{PC}$ firing rate is modulated in proportion to the duration, direction, or speed of the movement being generated (Shidara et al., 1993; Thier et al., 2000; Roitman et al., 2005; Medina and Lisberger, 2009). To determine whether there is a causal link between graded suppression of PC activity and movement kinematics, we systematically varied three parameters of the photostimulating light pulse: duration (Fig. $4 A, B$ ), intensity (Fig. $4 C, D$ ), and rise time (Fig. $4 E, F$ ). As illustrated in Figure $4 A$ (top), changing the duration of the light pulse caused a corresponding change in the duration of eyelid closure (blink duration; Fig. $4 B$; slope $=1.04, r=0.99, p \ll 0.0001)$ without affecting the maximum eyelid velocity (blink speed; Fig. $4 A$, bottom). In addition, we found that both the intensity (Fig. $4 D$; one-way ANOVA: $\left.F_{(2,76)}=4.4, p=0.015\right)$ and the rise time of the light pulse (Fig. $4 F$; one-way ANOVA: $F_{(2,42)}=11.1, p=0.0001$ ) influenced the time required to reach maximum eyelid closure. This finding is especially pertinent because previous studies have shown that the cerebellar cortex is necessary for adaptively controlling the timing of classically conditioned eyelid movements (Perrett et al., 1993; Medina et al., 2000; Koekkoek et al., 2003). In our experiments, the timing of the blink was regulated in two different ways: changing the intensity of photostimulation had a substantial effect on both the maximum eyelid closure achieved (blink size; Fig. $4 C$, top) and the speed of closure (blink speed; Fig. $4 C$, bottom). In contrast, the rise time of the light pulse had less effect on blink size (Fig. 4E, top), but influenced blink speed and the time at which maximum speed was reached (Fig. $4 E$, bottom). Therefore, each optogenetic manipulation revealed a different mechanism to control movement kinematics and fine tune the timing of motor output by adjusting how long, how much, and how many PCs are inhibited. 

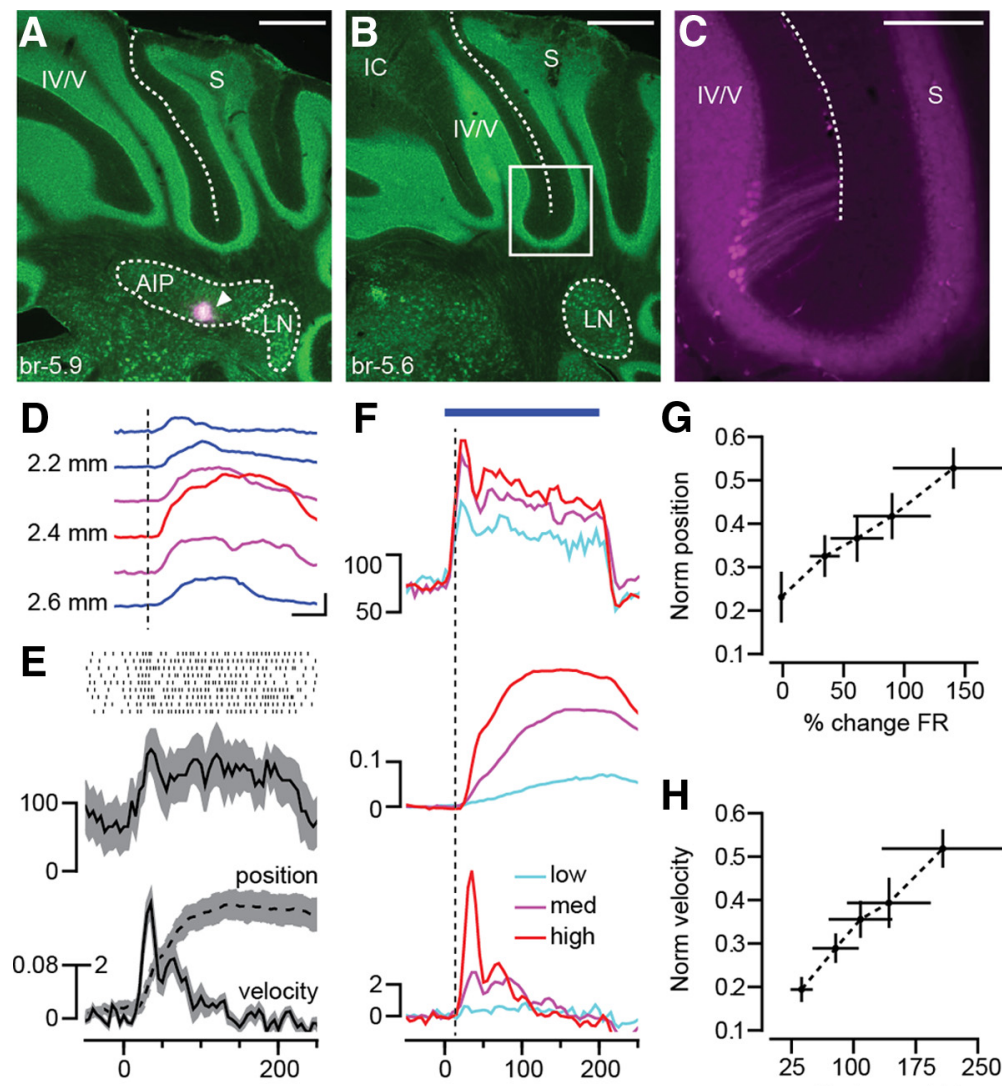

Time from laser onset (ms)
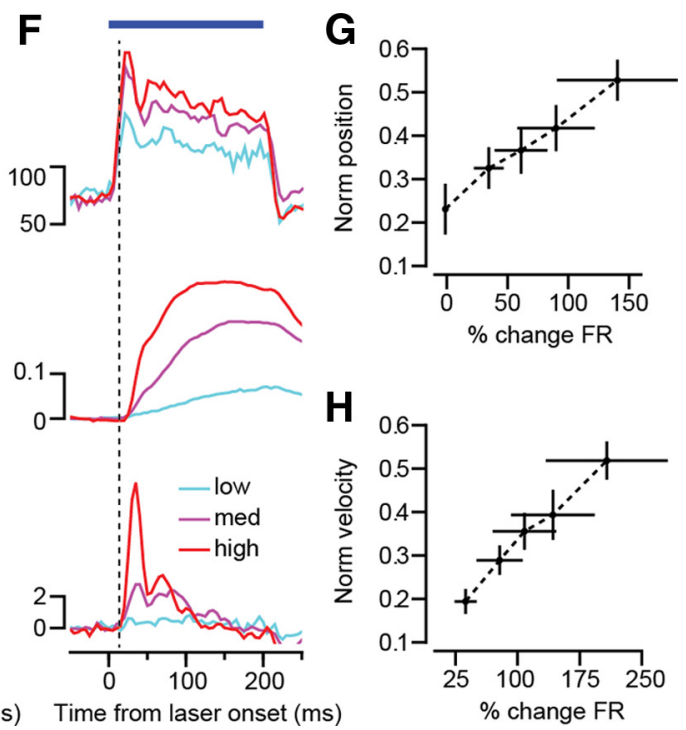

Figure 5. Photostimulation-driven disinhibition of DCN neurons is correlated with eyelid kinematics. Clusters of PCs retrogradely labeled from the injection site in the eyeblink-related DCN region (triangle in $\boldsymbol{A}$ ) were found inside the white box in $\boldsymbol{B}$ (magnified in $\boldsymbol{C}$. Scale bars: $\boldsymbol{A}$ and $\boldsymbol{B}, 500 \mu \mathrm{m} ; \boldsymbol{C}, 300 \mu \mathrm{m}$. AIP, anterior interpositus nucleus; IC, inferior colliculus; LN, lateral nucleus; $S$, lobule simplex. D, Blinks evoked during electrical microstimulation (200 ms, $5 \mu$ A; scale bar, 50 ms and 20\% FEC; dashed line indicates stimulus onset) at various depths around the DCN site in $\boldsymbol{A}$. $\boldsymbol{E}$, Raster and PSTH of example DCN neuron (top) and simultaneously recorded eyelid kinematics (bottom; position is in $\mathrm{FEC}$, outside axis; velocity is in $\mathrm{FEC} / \mathrm{s}$, inside axis) during photostimulation in eyeblink microzone of cerebellar cortex. $\boldsymbol{F}$, Population average PSTH of DCN neurons (top) and average position (middle; FEC) and velocity (bottom; FEC/s) for different light intensities ( $n=10$ neurons; light intensity as in Fig. 4C). Blue bar indicates photostimulation time, $200 \mathrm{~ms}$. Dashed line indicates movement onset. $\mathbf{G}$, Relationship between eyelid position and average percent change in firing rate for all recorded DCN neurons during the last 100 ms of photostimulation (binned based on firing rate quintiles for each neuron, regardless of laser intensity). $\boldsymbol{H}$, same as $\boldsymbol{G}$ but for eyelid velocity and DCN response during the first $100 \mathrm{~ms}$ of photostimulation. Error bars indicate SEM.

\section{Suppression of PC activity controls behavior via graded} disinhibition of DCN neurons

PCs are inhibitory projection neurons that convey the entire output of the cerebellar cortex (Fig. $1 A$ ) and are known to have a strong influence on the firing of their target cells in the DCN (Ito, 1984; Gauck and Jaeger, 2000; Alviña et al., 2008; Hoebeek et al., 2010; De Zeeuw et al., 2011; Person and Raman, 2012; Witter et al., 2013). How are the graded effects of photostimulation on a population of PCs decoded downstream to produce the observed behavior?

To answer this question, we recorded single-unit extracellular activity in a region of the anterior interpositus (AIP) nucleus of the DCN that we determined receives PC input from the eyeblink microzone of cerebellar cortex (Fig. 5A-C) and from which eyeblinks could be reliably evoked with very low-intensity electrical microstimulation (2-3 $\mu \mathrm{A}$ thresholds; Fig. 5D). In response to photostimulation within the eyeblink microzone of cerebellar cortex, individual neurons in this region of the AIP showed excitatory responses (example neuron in Fig. $5 E$ ) that were graded with the intensity of the light pulse (Fig. $5 F ; n=10$ neurons; median latency to $20 \%$ increase $=6 \mathrm{~ms}$; range $=4-30 \mathrm{~ms}$ ). The increased firing of AIP neurons cannot be caused by direct pho-

\section{Discussion}

tostimulation because nNOS-ChR2-BAC mice have no detectable expression of ChR2 in the DCN (Fig. 1B) and because DCN neurons in cerebellar slices from these mice are not activated by blue light (Fig. 1E). In fact, moving the tip of the optical fiber deeper into the cerebellum (closer to the DCN) eliminated the photostimulation-driven movements. Therefore, the elevated firing rate of AIP neurons shown in Figure 5, $E$ and $F$, must be a result of disinhibition caused by photostimulation-driven decreases in $\mathrm{PC}$ activity (Fig. 2B-E).

Because each DCN neuron receives converging input from many PCs (Person and Raman, 2012), we hypothesized that the firing of individual cells in the AIP should reflect the average effects of photostimulation and therefore be tightly linked to movement kinematics. To test this hypothesis, we recorded single units in the AIP while photostimulating in the eyeblink microzone of cerebellar cortex with light pulses of different intensities. We then analyzed the activity of each neuron with respect to eyelid kinematics on every photostimulation trial, sorting the firing rate modulation into quintiles regardless of light intensity (see Materials and Methods). Across our population of AIP cells, we found a strong linear correlation between firing rate and both the size (Fig. $5 G ; r=0.70 \pm$ $0.27 \mathrm{SD}, p=0.0002$ ) and speed (Fig. $5 \mathrm{H}$; $r=0.86 \pm 0.10 \mathrm{SD}, p=0.0004)$ of eyelid movements. This relationship suggests a relatively straightforward and direct mapping between graded suppression of PC population activity, disinhibition-driven increases in the firing of DCN neurons, and the control of movement kinematics.

We have shown that a brief and synchronized suppression in the spontaneous firing of PCs in the paravermal area of cerebellar cortex is sufficient to generate a variety of orofacial movements. The particular movement that is generated depends on the precise location of the PC population in which spontaneous activity is suppressed. Furthermore, our results demonstrate that the amount, duration, and spatial extent of PC firing suppression can be used as an effective control signal to sculpt the timing and kinematic properties of motor output via graded disinhibition of neurons in the DCN. In our experiments, it was not possible to determine whether the graded modulation of DCN activity and movement kinematics was achieved by varying the degree to which the firing of a select population of PCs was suppressed or by varying the total number of inhibited PCs. It is possible that, under normal conditions, both of these factors could be dynamically regulated to control movement with precision.

Our experiments targeted deep locations in paravermal lobules V and VI of cerebellar cortex. Although we did not conduct an exhaustive mapping examination of these areas, we found that 
different orofacial movements could be elicited by suppressing PC activity in contiguous zones separated from each other by $<300 \mu \mathrm{m}$. This is consistent with previous studies indicating the presence of a face representation in this region (Dow and Moruzzi, 1958; Ito, 1984; Manni and Petrosini, 2004). The short latencies of the evoked movements in our study are also consistent with the known connectivity: PCs in the paravermis project to the interpositus nucleus of the DCN, which has direct access to motoneurons via the magnocellular division of the red nucleus (Ito, 1984). In contrast, PCs in more lateral locations project to neurons in the dentate nucleus of the DCN, which are not directly connected to motoneurons but can modulate activity in a number of motor areas of the cerebral cortex via the thalamus (Ito, 1984). Transiently suppressing the spontaneous firing of these lateral PCs may have more subtle effects than reported here because their activity is thought to provide information about the current motor state but does not seem to contribute to the motor command directly (Miall et al., 2007). Indeed, recent work suggests that PC activity could play multiple roles in addition to directly controlling motor output (Medina, 2011), including providing a prediction of future movement kinematics (Pasalar et al., 2006) and serving as a teaching signal for downstream cells in the DCN (Pugh and Raman, 2006; Otis et al., 2012).

In using a cell-specific optogenetic approach, we have demonstrated that MLIs can suppress PC firing very effectively in vivo, leading to a quick, reliable, and precise disinhibition of downstream neurons in the DCN. This finding is in good agreement with in vitro experiments showing that the inhibitory action of MLIs is strong and very fast (Korn and Axelrad, 1980; Mittmann et al., 2005) and that synchronized pauses in PC activity as brief as $15 \mathrm{~ms}$ in duration are sufficient to elicit reliable and precisely timed spiking in the DCN (Gauck and Jaeger, 2000). There are other ways to suppress PC firing, but they may not be as effective or precise. For example, decreasing the excitatory drive provided by the parallel fiber input can reduce the net spiking output of the PC in some conditions (Lev-Ram et al., 2003; Mittmann and Häusser, 2007) but paradoxically increase it in others (Mittmann and Häusser, 2007; Steuber et al., 2007). In addition, activation of the climbing fiber input generates a complex spike in the PC, which is immediately followed by a brief pause (Thach, 1968). However, the downstream effects of these climbing fiber-related pauses are unclear: DCN neurons remain strongly inhibited by the complex spikes throughout the entire duration of the pause, resuming their firing only after the high spontaneous activity of the PCs has been restored (Hoebeek et al., 2010; Blenkinsop and Lang, 2011). Whether these other mechanisms for suppressing PC firing can be used by the cerebellum to control movement effectively and with precision is currently unknown.

The photostimulation parameters we used in our experiments caused a complete suppression of firing in many PCs located in the same microzone of cerebellar cortex, probably as a result of strong and synchronized activation of MLIs. Based on the idiosyncratic connectivity of MLIs, which is characterized by synchronizing synaptic inputs and selective inhibition of PCs located in the same parasagittal microzone (Gao et al., 2006; Jörntell et al., 2010), it has been suggested that such patterns of activity may occur naturally during normal behavior and could be responsible for driving learned movements (Jörntell et al., 2010). Indeed, it is known that during eyeblink conditioning many PCs learn to pause, completely suppressing their firing for hundreds of milliseconds during the generation of conditioned eyelid responses (Jirenhed et al., 2007). In addition, conditioning-related increases in the firing of DCN neurons are qualitatively similar in magnitude to the increases we measured during photostimulation (McCormick and Thompson, 1984; Aksenov et al., 2004; Chen and Evinger, 2006; Campolattaro et al., 2011). However, under normal learning conditions, DCN neurons may also be directly activated by new mossy fiber collaterals that could contribute to motor control by providing an additional excitatory drive beyond what is achieved by PC-mediated disinhibition alone (Medina et al., 2000; Ohyama et al., 2006; Boele et al., 2013).

Our findings provide support for the "disinhibition hypothesis" of cerebellar function (Albus, 1971; Ito, 1984, 2001), which is based on the assumption that suppression of PC activity plays a central role in the control of movement. However, it is clear that PC signals can exert control in other ways as well depending on how they are decoded downstream and whether they are ultimately used to activate or inhibit motoneurons (De Zeeuw et al., 2011). Indeed, there seems to be an extraordinary degree of flexibility built into the system. For example, a sudden increase in PC firing can be used to suppress the activity of DCN neurons and trigger a subsequent "rebound" movement (Dow and Moruzzi, 1958; Witter et al., 2013), but it can also be used to entrain the DCN neurons to a particular frequency if the spikes of the PC population are synchronized (Person and Raman, 2012). In addition, DCN neurons receiving PC input are connected to motoneurons in many different ways that often include indirect pathways via inhibitory projections (Antal et al., 1992). The inherent multiplicity built into the cerebellar system may help explain why, in some cases, strong and synchronous activation of PCs with electrical microstimulation can elicit muscle contraction (Ito, 1984) and why transient increases in PC firing are just as prominent as decreases in many motor tasks (Roitman et al., 2005; Medina and Lisberger, 2009; Kojima et al., 2010; Cao et al., 2012). As suggested by others (Houk et al., 1996; Holdefer and Miller, 2009; Park et al., 2012), reciprocal increases and decreases in the activity of neighboring PCs may be particularly useful for fine tuning motor commands initiated elsewhere and for coordinating the action of agonist and antagonist muscles with precision.

Relaying information by transiently suppressing the activity of inhibitory neurons is not unique to the cerebellum and may indeed represent a fundamental coding principle in the brain, particularly for the control of movement. Pauses in the spontaneous firing of inhibitory neurons have been linked to motor control in a variety of subcortical areas, including the output stations of the basal ganglia (Chevalier and Deniau, 1990), the magnus (Hellman and Mason, 2012) and interpositus (Büttner-Ennever et al., 1988) divisions of the raphe, the nucleus accumbens (Krause et al., 2010), and the spinal cord (Johnson et al., 2012). In the prevailing view, these disinhibitory signals are used to gate, facilitate, adjust, or shape the motor command, but they are not able to drive movement by themselves. In our experiments, evoked movements were reliable but relatively small, which may indicate that in natural conditions disinhibitory PC signals may play a modulatory role. Nonetheless, our finding that suppression of PC firing is sufficient to elicit movement suggests that, in addition to its classic role in modulating and regulating motor output (Dow and Moruzzi, 1958), the cerebellar cortex may also contribute more directly to the generation of motor commands.

\section{References}

Aksenov D, Serdyukova N, Irwin K, Bracha V (2004) GABA neurotransmission in the cerebellar interposed nuclei: involvement in classically conditioned eyeblinks and neuronal activity. J Neurophysiol 91:719-727. CrossRef Medline 
Albus J (1971) A theory of cerebellar function. Math Biosci 10:25-61. CrossRef

Alviña K, Walter JT, Kohn A, Ellis-Davies G, Khodakhah K (2008) Questioning the role of rebound firing in the cerebellum. Nat Neurosci 11: 1256-1258. CrossRef Medline

Antal M, Sholomenko GN, Moschovakis AK, Storm-Mathisen J, Heizmann CW, Hunziker W (1992) The termination pattern and postsynaptic targets of rubrospinal fibers in the rat spinal cord: a light and electron microscopic study. J Comp Neurol 325:22-37. CrossRef Medline

Asrican B, Augustine GJ, Berglund K, Chen S, Chow N, Deisseroth K, Feng G, Gloss B, Hira R, Hoffmann C, Kasai H, Katarya M, Kim J, Kudolo J, Lee LM, Lo SQ, Mancuso J, Matsuzaki M, Nakajima R, Qiu L, et al. (2013) Next-generation transgenic mice for optogenetic analysis of neural circuits. Front Neural Circuits 7:160. CrossRef Medline

Bastian AJ, Martin TA, Keating JG, Thach WT (1996) Cerebellar ataxia: abnormal control of interaction torques across multiple joints. J Neurophysiol 76:492-509. Medline

Blenkinsop TA, Lang EJ (2011) Synaptic action of the olivocerebellar system on cerebellar nuclear spike activity. J Neurosci 31:14708-14720. CrossRef Medline

Boele H-J, Koekkoek SK, De Zeeuw CI, Ruigrok TJ (2013) Axonal sprouting and formation of terminals in the adult cerebellum during associative motor learning. J Neurosci 33:17897-17907. CrossRef Medline

Büttner-Ennever JA, Cohen B, Pause M, Fries W (1988) Raphe nucleus of the pons containing omnipause neurons of the oculomotor system in the monkey, and its homologue in man. J Comp Neurol 267:307-321. CrossRef Medline

Campolattaro MM, Kashef A, Lee I, Freeman JH (2011) Neuronal correlates of cross-modal transfer in the cerebellum and pontine nuclei. J Neurosci 31:4051-4062. CrossRef Medline

Cao Y, Maran SK, Dhamala M, Jaeger D, Heck DH (2012) Behavior-related pauses in simple-spike activity of mouse Purkinje cells are linked to spike rate modulation. J Neurosci 32:8678-8685. CrossRef Medline

Chen FP, Evinger C (2006) Cerebellar modulation of trigeminal reflex blinks: interpositus neurons. J Neurosci 26:10569-10576. CrossRef Medline

Chettih SN, McDougle SD, Ruffolo LI, Medina JF (2011) Adaptive timing of motor output in the mouse: the role of movement oscillations in eyelid conditioning. Front Integr Neurosci 5:72. CrossRef Medline

Chevalier G, Deniau JM (1990) Disinhibition as a basic process in the expression of striatal functions. Trends Neurosci 13:277-280. CrossRef Medline

De Zeeuw CI, Hoebeek FE, Bosman LW, Schonewille M, Witter L, Koekkoek SK (2011) Spatiotemporal firing patterns in the cerebellum. Nat Rev Neurosci 12:327-344. CrossRef Medline

Dow RS, Moruzzi G (1958) The physiology and pathology of the cerebellum. Minneapolis: University of Minnesota.

Gao W, Chen G, Reinert KC, Ebner TJ (2006) Cerebellar cortical molecular layer inhibition is organized in parasagittal zones. J Neurosci 26:83778387. CrossRef Medline

Garcia KS, Steele PM, Mauk MD (1999) Cerebellar cortex lesions prevent acquisition of conditioned eyelid responses. J Neurosci 19:10940-10947. Medline

Gauck V, Jaeger D (2000) The control of rate and timing of spikes in the deep cerebellar nuclei by inhibition. J Neurosci 20:3006-3016. Medline

Hellman KM, Mason P (2012) Opioids disrupt pro-nociceptive modulation mediated by raphe magnus. J Neurosci 32:13668-13678. CrossRef Medline

Hesslow G (1994) Correspondence between climbing fibre input and motor output in eyeblink-related areas in cat cerebellar cortex. J Physiol 476: 229-244. Medline

Hoebeek FE, Witter L, Ruigrok TJ, De Zeeuw CI (2010) Differential olivocerebellar cortical control of rebound activity in the cerebellar nuclei. Proc Natl Acad Sci U S A 107:8410-8415. CrossRef Medline

Holdefer RN, Miller LE (2009) Dynamic correspondence between Purkinje cell discharge and forelimb muscle activity during reaching. Brain Res 1295:67-75. CrossRef Medline

Houk JC, Buckingham JT, Barto AG (1996) Models of the cerebellum and motor learning. Behav Brain Sci 19:368-383. CrossRef

Ito M (1984) The cerebellum and neural control. San Diego: Raven.

Ito M (2001) Cerebellar long-term depression: characterization, signal transduction, and functional roles. Physiol Rev 81:1143-1195. Medline
Ivry RB, Keele SW (1989) Timing functions of the cerebellum. J Cogn Neurosci 1:136-152. CrossRef Medline

Jirenhed DA, Bengtsson F, Hesslow G (2007) Acquisition, extinction, and reacquisition of a cerebellar cortical memory trace. J Neurosci 27:24932502. CrossRef Medline

Johnson MD, Hyngstrom AS, Manuel M, Heckman CJ (2012) Push-pull control of motor output. J Neurosci 32:4592-4599. CrossRef Medline

Jörntell H, Bengtsson F, Schonewille M, De Zeeuw CI (2010) Cerebellar molecular layer interneurons-computational properties and roles in learning. Trends Neurosci 33:524-532. CrossRef Medline

Koekkoek SK, Hulscher HC, Dortland BR, Hensbroek RA, Elgersma Y, Ruigrok TJ, De Zeeuw CI (2003) Cerebellar LTD and learningdependent timing of conditioned eyelid responses. Science 301:17361739. CrossRef Medline

Kojima Y, Soetedjo R, Fuchs AF (2010) Changes in simple spike activity of some Purkinje cells in the oculomotor vermis during saccade adaptation are appropriate to participate in motor learning. J Neurosci 30:37153727. CrossRef Medline

Korn H, Axelrad H (1980) Electrical inhibition of Purkinje cells in the cerebellum of the rat. Proc Natl Acad Sci U S A 77:6244-6247. CrossRef Medline

Krause M, German PW, Taha SA, Fields HL (2010) A pause in nucleus accumbens neuron firing is required to initiate and maintain feeding. J Neurosci 30:4746-4756. CrossRef Medline

Lev-Ram V, Mehta SB, Kleinfeld D, Tsien RY (2003) Reversing cerebellar long-term depression. Proc Natl Acad Sci U S A 100:15989-15993. CrossRef Medline

Manni E, Petrosini L (2004) A century of cerebellar somatotopy: a debated representation. Nat Rev Neurosci 5:241-249. CrossRef Medline

Manto M-U, Pandolfo M (2002) The cerebellum and its disorders. Cambridge: Cambridge UP.

Mauk MD, Ruiz BP (1992) Learning-dependent timing of Pavlovian eyelid responses: differential conditioning using multiple interstimulus intervals. Behav Neurosci 106:666-681. CrossRef Medline

Mauk MD, Medina JF, Nores WL, Ohyama T (2000) Cerebellar function: coordination, learning or timing? Curr Biol 10:R522-5. CrossRef Medline

McCormick DA, Thompson RF (1984) Neuronal responses of the rabbit cerebellum during acquisition and performance of a classically conditioned nictitating membrane-eyelid response. J Neurosci 4:2811-2822. Medline

Medina JF (2011) The multiple roles of Purkinje cells in sensori-motor calibration: to predict, teach and command. Curr Opin Neurobiol 21:616622. CrossRef Medline

Medina JF, Lisberger SG (2009) Encoding and decoding of learned smoothpursuit eye movements in the floccular complex of the monkey cerebellum. J Neurophysiol 102:2039-2054. CrossRef Medline

Medina JF, Mauk MD (2000) Computer simulation of cerebellar information processing. Nat Neurosci 3:1205-1211. CrossRef Medline

Medina JF, Nores WL, Ohyama T, Mauk MD (2000) Mechanisms of cerebellar learning suggested by eyelid conditioning. Curr Opin Neurobiol 10:717-724. CrossRef Medline

Miall RC, Christensen LO, Cain O, Stanley J (2007) Disruption of state estimation in the human lateral cerebellum. PLoS Biol 5:e316. CrossRef Medline

Mittmann W, Häusser M (2007) Linking synaptic plasticity and spike output at excitatory and inhibitory synapses onto cerebellar Purkinje cells. J Neurosci 27:5559-5570. CrossRef Medline

Mittmann W, Koch U, Häusser M (2005) Feed-forward inhibition shapes the spike output of cerebellar Purkinje cells. J Physiol 563:369-378. CrossRef Medline

Mostofi A, Holtzman T, Grout AS, Yeo CH, Edgley SA (2010) Electrophysiological localization of eyeblink-related microzones in rabbit cerebellar cortex. J Neurosci 30:8920-8934. CrossRef Medline

Noda H, Suzuki DA (1979) The role of the flocculus of the monkey in saccadic eye movements. J Physiol 294:317-334. Medline

Ohyama T, Nores WL, Medina JF, Riusech FA, Mauk MD (2006) Learninginduced plasticity in deep cerebellar nucleus. J Neurosci 26:12656-12663. CrossRef Medline

Otis TS, Mathews PJ, Lee KH, Maiz J (2012) How do climbing fibers teach? Front Neural Circuits 6:1-3. CrossRef Medline

Park SM, Tara E, Khodakhah K (2012) Efficient generation of reciprocal signals by inhibition. J Neurophysiol 107:2453-2462. CrossRef Medline 
Pasalar S, Roitman AV, Durfee WK, Ebner TJ (2006) Force field effects on cerebellar Purkinje cell discharge with implications for internal models. Nat Neurosci 9:1404-1411. CrossRef Medline

Perrett SP, Ruiz BP, Mauk MD (1993) Cerebellar cortex lesions disrupt learning-dependent timing of conditioned eyelid responses. J Neurosci 13:1708-1718. Medline

Person AL, Raman IM (2012) Purkinje neuron synchrony elicits timelocked spiking in the cerebellar nuclei. Nature 481:502-505. CrossRef Medline

Pugh JR, Raman IM (2006) Potentiation of mossy fiber EPSCs in the cerebellar nuclei by NMDA receptor activation followed by postinhibitory rebound current. Neuron 51:113-123. CrossRef Medline

Roitman AV, Pasalar S, Johnson MT, Ebner TJ (2005) Position, direction of movement, and speed tuning of cerebellar Purkinje cells during circular manual tracking in monkey. J Neurosci 25:9244-9257. CrossRef Medline

Shidara M, Kawano K, Gomi H, Kawato M (1993) Inverse-dynamics model eye movement control by Purkinje cells in the cerebellum. Nature 365: 50-52. CrossRef Medline

Shin SL, De Schutter E (2006) Dynamic synchronization of Purkinje cell simple spikes. J Neurophysiol 96:3485-3491. CrossRef Medline

Spencer RM, Zelaznik HN, Diedrichsen J, Ivry RB (2003) Disrupted timing of discontinuous but not continuous movements by cerebellar lesions. Science 300:1437-1439. CrossRef Medline
Steuber V, Mittmann W, Hoebeek FE, Silver RA, De Zeeuw CI, Häusser M, De Schutter E (2007) Cerebellar LTD and pattern recognition by Purkinje cells. Neuron 54:121-136. CrossRef Medline

Thach WT (1968) Discharge of Purkinje and cerebellar nuclear neurons during rapidly alternating arm movements in the monkey. J Neurophysiol 31:785-797. Medline

Thach WT, Goodkin HP, Keating JG (1992) The cerebellum and the adaptive coordination of movement. Annu Rev Neurosci 15:403-442. CrossRef Medline

Thier P, Dicke PW, Haas R, Barash S (2000) Encoding of movement time by populations of cerebellar Purkinje cells. Nature 405:72-76. CrossRef Medline

Tsuda S, Kee MZ, Cunha C, Kim J, Yan P, Loew LM, Augustine GJ (2013) Probing the function of neuronal populations: combining micromirrorbased optogenetic photostimulation with voltage-sensitive dye imaging. Neurosci Res 75:76-81. CrossRef Medline

Walter JT, Alviña K, Womack MD, Chevez C, Khodakhah K (2006) Decreases in the precision of Purkinje cell pacemaking cause cerebellar dysfunction and ataxia. Nat Neurosci 9:389-397. CrossRef Medline

Witter L, Canto CB, Hoogland TM, de Gruijl JR, De Zeeuw CI (2013) Strength and timing of motor responses mediated by rebound firing in the cerebellar nuclei after Purkinje cell activation. Front Neural Circuits 7:133. CrossRef Medline 